\title{
ATUAÇÃO DO ENFERMEIRO COMO EDUCADOR EM SAÚDE DE PRIMEIROS SOCORROS EM ESCOLA DE ENSINO INFANTIL
}

\section{NURSE'S ROLE AS A FIRST AID HEALTH EDUCATOR IN NURSERY SCHOOL}

\author{
Katia de Jesus Ferreira', Beatriz Essenfelder Borges ${ }^{1}{ }^{2 *}$, Antonio Carlos Schwiderski' \\ 'Faculdades Integradas Santa Cruz de Curitiba, Curitiba, Paraná, Brasil \\ ${ }^{2}$ Faculdades Pequeno Príncipe de Curitiba, Curitiba, Paraná, Brasil \\ *Autor correspondente: Beatriz Essenfelder Borges. Rua Amazonas 677, Água Verde, Curitiba. Telefone: 41 \\ 99997531 1. Email: biaessenfelder@gmail.com
}

\section{RESUMO}

Introdução: Os acidentes infantis são uma importante fonte de preocupação por serem causas crescentes de mortalidade e invalidez no Brasil. Nesse contexto, faz-se necessário o conhecimento básico em primeiros socorros (PS), uma vez que são fundamentais ao salvamento de vidas e redução de sequelas, muitas vezes, irreversíveis. No ambiente escolar, geralmente, o professor é o primeiro a presenciar o acidente, sendo importante que esteja apto a efetuar uma assistência imediata e de qualidade. Objetivo: Identificar o nível de conhecimento em PS dos professores da Educação Infantil de uma escola privada, localizada na cidade de Curitiba (PR). Metodologia: Trata-se de uma pesquisa-ação, com caráter descritivo de abordagem qualitativa, realizada em uma escola privada de Educação Infantil, localizada no município de Curitiba (PR). A amostra foi composta por 11 colaboradores, de idade superior a 18 anos, vinculados à instituição há, pelo menos, três meses. Para a coleta de dados, foram realizadas entrevistas contendo nove questões semiestruturadas, além disso, realizaram-se testes simulando acidentes com as principais emergências possíveis em ambiente escolar. Resultados: Evidenciouse que a amostra não detém conhecimentos suficientes para o atendimento em PS infantil, principalmente quando realizadas as simulações. Conclusão: Observou-se que os colaboradores demonstraram dificuldades frente ao acidente infantil e, a partir dessas situações, o examinador sugeriu algumas recomendações para que a própria instituição pudesse buscar melhorias nesse quesito. Devido ao exposto pode-se afirmar que a inclusão do enfermeiro em instituições de ensino infantil, mesmo que ocasionalmente, pode influenciar diretamente o atendimento, em saúde, a essas crianças.

Palavras-chaves: Primeiros Socorros; Educação em saúde; Enfermagem.

\section{ABSTRACT}

Introduction: Childhood accidents are an important source of concern because of the growing mortality and disability's cause in Brazil. In this context, the basic knowledge is necessary in first aid (FA), being fundamental in saving lives and reducing sequelae. In the school environment, the teacher is usually the first to witness the accident, it is important to be able to provide immediate quality assistance. Objective: To identify the level of FA knowledge of early childhood educators in a private school in Curitiba PR. Methodology: This is a qualitative approachresearch with a descriptive character, held at a private school, located in Curitiba (PR). The sample consisted of 11 employees over the age of 18, linked to the institution for at least three months. For data collection, in an interview it was applied nine semi-structured question and conducted tests 
simulating accidents containing the major emergencies in the school environment. Results: Evidencingthat the sample does not have sufficient knowledge for the care in child FA, especially when the simulations were performed. Conclusion: It was observed that the collaborators showed difficulties in relation to the attitudes towards the childhood accident and from these situationsthe examiner suggested some recommendations for the institution to look for ways to improve in this regard. Due to the above, it can be stated atedthat that the nurse's inclusion in early childhood institutions, even occasionally, can directly influence the health care of these children.

Keywords: First aid; Health education; Nursing.

\section{INTRODUÇÃO}

Segundo o Relatório Mundial sobre Prevenção de Acidentes com Crianças e Adolescentes, lançado em dezembro de 2008, pela Organização Mundial de Saúde (OMS) e UNICEF, 830 mil crianças morrem anualmente no mundo em decorrência de acidentes. A principal causa de mortalidade e incapacidade é o trauma, sendo responsável por mais óbitos do que todas as doenças combinadas e um dos maiores problemas de saúde pública mundial. (RNPI, 2014).

O Brasil juntamente com outros países apresenta elevados números de óbitos ocasionados por acidentes em menores de 15 anos. Segundo dados oficiais do DATASUS / Ministério da Saúde e IBGE (Instituto Brasileiro de Geografia e Estatística), entre os anos de 2008 e 2015, observou-se que no país os acidentes na infância e adolescência foram responsáveis por 625.819 internamentos (CRIANÇA SEGURA, 2016).

No ambiente escolar são frequentes alguns tipos de acidentes, e esses podem ocorrer a qualquer momento, principalmente no horário de intervalo ou das refeições, devido à maior agitação dos alunos. Por esse motivo, os professores necessitam ser orientados para atuar nos PS, possibilitando o salvamento de vidas e reduzindo sequelas, muitas vezes irreversíveis (SENA; RICA; VIANA, 2008, SILVA et al., 2017).

De acordo com Siqueira e colaboradores (2011), as escolas e os professores têm um papel importante na promoção da saúde, na prevenção de doenças e acidentes entre as crianças. Em muitas situações, a falta de conhecimento acarreta inúmeros problemas, como estado de pânico, manipulação incorreta e solicitação desnecessária do socorro especializado em emergência. É nesse contexto que se torna importante o conhecimento sobre os PS entre professores, educadores e funcionários de escolas de Educação Infantil. (CABRAL, 2015).

A necessidade de identificar o nível de conhecimento dos professores em PS e a implantação de planos de emergência, dentro do âmbito escolar, é de suma importância, pois permite o socorro imediato aos alunos, a promoção de saúde, a prevenção de doenças e acidentes entre crianças e adolescentes (MAIA et al., 2012; CALANDRIM et al.,2017).

Nesse contexto a educação em saúde apresenta-se como estratégia eficaz para o enfrentamento do déficit de conhecimento dos professores acerca da temática. Dessa forma, o enfermeiro ocupa uma posição estratégica para a educação em saúde, acerca dos PS na escola, já que a Enfermagem atua no Programa Saúde na Escola (PSE), que preza pela promoção da saúde escolar (BRASIL, 2007). 
A partir dessas considerações, objetivou-se identificar o nível de conhecimento em PS dos professores da Educação Infantil de uma escola privada, localizada na cidade de Curitiba (PR). Pretendeuse responder ao seguinte questionamento: os professores da Educação Infantil estão preparados para realizar os PS em momentos de urgência e emergência?

\section{METODOLOGIA}

O presente estudo é uma pesquisa-ação que além de compreender, consiste em intervir na situação (THIOLLENT, 2000; THIOLLENT, 2011), com caráter descritivo e abordagem qualitativa, onde foi possível responder a questões particulares, preocupando-se com um nível de realidade que não pode ser quantificado (MINAYO, 2004; MINAYO, 2013).

O estudo foi realizado nas dependências de uma escola privada de Educação Infantil, localizada no município de Curitiba (PR). A amostra foi composta de 11 indivíduos voluntários, entre eles educadores, professores e colaboradores vinculados, pelo menos, há três meses à instituição, com idade igual ou superior a 18 anos.

A pesquisa foi dividida em duas fases: a primeira composta por entrevista individual contendo nove questões semiestruturadas, a respeito dos PS e prevenção de acidentes, sendo adequadas a cada entrevistado, se necessário.

Já na segunda fase foram aplicadas quatro simulações de situações de emergência comuns nas escolas, dentre elas: convulsão, desmaio, epistaxe (sangramento nasal) e engasgo. Nessa fase foram observados os procedimentos executados pelos participantes individualmente, utilizando checklist estruturado pela própria pesquisadora, apoiando-se teoricamente em protocolo do suporte básico de vida do SAMU _Ministério da Saúde (MS) (BRASIL, 2016).

Após a atuação dos participantes, realizou-se uma roda de conversa, onde se explicou o passo a passo de medidas corretas executadas em cada situação. Demonstrando que ao desempenhar uma intervenção de forma inadequada, pode-se agravar a situação ou expor, desnecessariamente, a criança a fatores de risco. A coleta de dados contou com o auxílio de um equipamento de mídia para gravação de áudio, a fim de facilitar a análise.

O estudo foi realizado somente após a aprovação pelo Comitê de Ética e Pesquisa do Instituto Paranaense de Otorrinolaringologia (IPO), com parecer de número 2.912.053. Os indivíduos participantes receberam o Termo de Consentimento Livre Esclarecido (TCLE), havendo tempo adequado para leitura, compreensão e esclarecimento de dúvidas.

Os dados foram obtidos por meio de análise temática, tratados em etapas, sendo elas: a pré-análise, a exploração do material e, por fim, o tratamento dos resultados obtidos e sua interpretação. Para manter o sigilo dos participantes, as respostas de cada voluntário foram categorizadas por funcionário, representados da seguinte maneira: F1, F2, F3, etc.

\section{RESULTADOS E DISCUSSÃO}

A pesquisa foi realizada em uma escola particular de Educação Infantil, que atende 123 crianças com idade entre um e cinco anos. A instituição conta com 22 funcionários trabalhando sob regime de 40 horas semanais. 


\section{$1^{a}$ Fase da pesquisa: Caracterização da amostra e entrevista}

A primeira parte do instrumento de coleta buscou identificar características da população estudada, conforme ilustrado na tabela1:

TABELA 1: Caracterização da amostra.

\begin{tabular}{llc}
\multicolumn{1}{c}{ Variáveis } & \multicolumn{1}{c}{ Descrição } & Frequência \\
Sexo & Feminino & 11 \\
& Masculino & 0 \\
Faixa etária & $23-27$ & 6 \\
(em anos) & $28-30$ & 3 \\
Vínculo funcional com a & $38-45$ & 2 \\
instituição & $0-2$ & 5 \\
(em anos) & $3-5$ & 4 \\
& $6-8$ & 2 \\
Cargo/ & Professoras & 8 \\
Função & Regente/auxiliar & 2 \\
& Equipe administrativa & 2 \\
& Pedagoga/direção & 1
\end{tabular}

Fonte: AUTORA (2018).

A presença expressiva do gênero feminino, principalmente na Educação Infantil, é um reflexo da cultura de feminização do magistério, que teve início na era capitalista, momento em que a mulher deixou o lar para trabalhar em fábricas, precisando de alguém que a substituísse à altura na educação de seus filhos, atribuiu-se à professora o título de mãe substituta (VASCONCELOS; POCAHY, 2013).

A análise temática possibilitou a divisão das questões em cinco categorias, já que algumas perguntas tratavam do mesmo assunto, conforme descritas na tabela 2:

Tabela 2: Demonstrativo das categorias temáticas.

\begin{tabular}{|c|c|}
\hline CATEGORIAS & QUESTÕES ANALISADAS \\
\hline $1^{a}$ Acidentes ocorridos na escola & $\begin{array}{l}\text { Ocorreu algum evento na escola presenciado por você e que o } \\
\text { considerou um acidente infantil? Se sim, qual foi a sua reação? } \\
\text { Em quais momentos foram mais comuns esses incidentes? } \\
\text { O que você entende por acidente? }\end{array}$ \\
\hline $2^{a}$ Responsabilidade pelo atendimento & $\begin{array}{l}\text { Quando ocorre algum tipo de acidente com crianças na escola, quem } \\
\text { as socorre? }\end{array}$ \\
\hline $3^{a}$ Conduta após o acidente & $\begin{array}{l}\text { Há uma sequência ou norma para seguir nesses momentos? } \\
\text { Existe um local destinado ao atendimento? } \\
\text { Existem registros específicos dos acidentes ocorridos na escola? }\end{array}$ \\
\hline $\begin{array}{l}4^{a} \text { Presenciar situação que exigiu } \\
\text { conhecimentos básicos de PS }\end{array}$ & $\begin{array}{l}\text { Você teve algum tipo de treinamento de primeiros socorros? } \\
\text { Existe na instituição esse tipo de treinamento? } \\
\text { Alguma situação exigiu conhecimento de PS? }\end{array}$ \\
\hline $\begin{array}{l}5^{a} \text { Importância e necessidade da presença do } \\
\text { profissional enfermeiro }\end{array}$ & Você considera importante a presença do enfermeiro na escola? \\
\hline
\end{tabular}

Fonte: Autora (2018).

\section{$1^{\text {a }}$ Categoria: Acidentes ocorridos na escola}

Durante a avaliação qualitativa das respostas, a primeira categoria analisada foi referente à ocorrência de acidentes na escola, uma vez que se ocorrido neste ambiente, além de trazer transtornos para a instituição pode gerar problemas relacionados à responsabilidade legal, visto que ao 
atender um aluno, vítima de acidente, o professor acaba deixando os outros de lado, facilitando a ocorrência de outro acidente durante a sua ausência (LINO et al., 2018).

Observou-se, nesta categoria, que mais de $72 \%$ dos participantes responderam que não presenciaram nenhum acidente ocorrido na escola, conforme demonstram as afirmações:

“(...) não, não que eu lembre, acidente é uma coisa muito grave (F1).

“(...) não aconteceu nenhum acidente envolvendo crianças, não que eu saiba" (F7).

Porém, foi constatado que os mesmos detêm conhecimento insatisfatório a respeito do conceito de acidente, uma vez que em outra questão aplicada, alguns participantes relataram que houve momentos onde incidentes ocorreram, surgindo a necessidade, por parte do avaliador, de questioná-los sobre o que entendiam por acidente, a fim de elucidar a situação.

Nesse contexto observou-se que, grande parte da amostra, desconhece o conceito de acidente, pois apenas $27 \%$ dos participantes demonstraram conhecer o significado real da palavra.

Esse aspecto vem ao encontro do que Machado e seus colaboradores (2017), assim como Costa e demais autores (2015) referem, acerca do pouco conhecimento em relação aos cuidados de saúde, em específico no que tange à prevenção de acidentes por parte dos professores de Educação Infantil, destacando que essa temática foi abordada de forma precária nos cursos de formação profissional.

Coelho e Silva (2011) ressaltam que o professor é um elemento muito importante na prevenção dos acidentes, afinal, ele convive diariamente com os alunos na realidade social e cultural, tendo assim, a possibilidade de planejar e desenvolver atividades preventivas (CABRAL, 2015).

Em relação aos locais e momentos em que mais acontecem os acidentes com as crianças, em ambiente escolar, 90\% das participantes responderam ser durante os momentos de recreação, e destacam as quedas como os principais eventos:

“(...) só acontecem os mais simples, como quedas, no parque, quando eles estão brincando, porque a maioria das atividades é direcionada, mas só acontecem quando é atividade livre..." (F10).

Lino e seus colaboradores (2018) enfatizam que os momentos de recreação são mais propícios à ocorrência de acidentes, devido à agitação das crianças. Afirmam ainda serem as quedas responsáveis por altos índices de acidentes infantis, sendo consideradas como o tipo mais comum de acidente, não intencional, mas evitável, e quanto mais alta a superfície em que ocorrer, maior é a probabilidade de lesões físicas e emocionais (SILVA et al., 2017).

Esses resultados corroboram com dados do Projeto VIVA do Ministério da Saúde. O referido estudo apontou que dos 6.897 acidentes que envolveram crianças entre zero e nove anos, a maioria possuía causas mais comuns associadas, em primeiro lugar, às quedas, seguidas de queimaduras, ferimentos perfurocortantes, acidentes com animais, corpo estranho e outros (MALTA et al., 2012, SIEBENEICHLER; HAHN, 2014).

\section{$2^{a}$ Categoria: Responsabilidade pelo atendimento}

A segunda categoria evidenciada neste estudo diz respeito à responsabilidade do atendimento prestado às crianças vítimas de acidentes. Os entrevistados foram unânimes ao afirmar que o professor é responsável pelo primeiro atendimento das crianças acidentadas na escola, pois é quem o presencia, como demonstrado nas respostas abaixo:

“(...) são sempre as professoras, a primeira pessoa que estiver por perto na hora... tanto faz... seja de qualquer turma" (F.1). 
“(...) são sempre as professoras mesmo, elas que socorrem, pois normalmente estão no local do acidente" (F.6).

Calandrim e colaboradores (2017) ressaltam a importância de determinar a conscientização, atitudes e práticas de professores sobre PS, destacando serem eles muitas vezes os primeiros indivíduos a presenciar emergências médicas com crianças no ambiente escolar.

Coelho e Silva (2011) e Cabral (2015), afirmam que o conhecimento das experiências dos professores e cuidadores, quanto ao atendimento a ocorrências de acidentes é relevante, uma vez que esses profissionais são responsáveis pelo processo de aprendizagem e, também, pelos cuidados em caso de acidentes.

Fato esse que ainda corrobora com o estudo de Malta e colaboradores (2012), os quais observaram que o conhecimento sobre PS é importante para uma tomada de decisão que vise à prevenção de agravos (CALANDRIM et al., 2017).

\section{$3^{a}$ Categoria: Conduta após o acidente}

A terceira categoria abrange a conduta dos profissionais após o acidente, por meio de normas e registros específicos para atendimento às crianças. Segundo as entrevistadas, na ocorrência de um evento mais grave, a conduta emergencial dá-se na secretaria, devido à existência de uma caixa de OS nesse local, conforme os relatos a seguir:

“(...) quando acontece alguma coisa mais grave a gente leva lá na secretaria, porque lá tem a caixinha de primeiros socorros" (F5).

“(...) inicialmente as professoras socorrem, dai se for preciso usar um curativo ou algo do tipo, a gente leva na secretaria" (F3).

“(...) na minha sala houve um episódio de desmaio, eu entrei em pânico, espanto, medo eu peguei ele no colo e sai correndo até a direção" (F9).

Porém, para Tinoco, Reis e Freitas (2014) as instituições não possuem material básico para a realização dos PS, recursos principais e essenciais para ao atendimento dessas ocorrências, sendo necessários à preservação e suporte da saúde dos infantes e dos professores (RITTER et al., 2013).

Durante os questionamentos o avaliador indagou a respeito da existência de algum registro específico após o incidente, como atas, cadernos e livros. No entanto, foi-lhe revelado não haver um procedimento específico de atendimento ou de notificação dos acidentes ocorridos arquivados na escola, apenas relatos dos acontecimentos na agenda dos alunos.

"(...) se for grave acho que em ata... não sei... eu nunca fiz... mas parece que teremos um registro de sala..." (F3).

“(...) não sei se tem, eu avisei via agenda..." (F9).

Essa postura, no entanto, diverge das adotadas pelas instituições públicas, as quais exigem o registro, intitulado "ocorrência". O qual, além de ser realizado após incidentes na escola, deve ser feito caso a criança venha de casa apresentando algo de anormal. O registro tem como finalidade dar respaldo à instituição e também para segurança da criança, justificada pelo amparo da Lei ${ }^{\circ}$ 8.069, de 13 de julho de 1990 (BRASIL, 1990), conhecida como Estatuto da Criança e do Adolescente (ECA), a qual dispõe sobre a proteção integral à criança e ao adolescente. (BRASIL, 1990). 


\section{$4^{a}$ Categoria: Presenciar situação que exigiu conhecimentos básicos de OS}

Na quarta categoria observou-se um fato revelador, dez das onze participantes afirmaram já ter presenciado uma situação que exigiu conhecimentos básicos de PS. No entanto, durante a entrevista notou-se que nem todos os colaboradores da escola possuíam noções dos princípios básicos específicos em acidentes infantis, com exceção de um depoimento:

“(..) nós tivemos uma palestra básica com os bombeiros, principalmente sobre evacuações durante incêndio e o que realizar em casos de afogamento" (F1).

"(...) algumas de nós foram escolhidas para um "curso" simples de primeiros socorros, onde abordavam temas como: afogamento, incêndio e parada cardiovascular" (F4).

"(...) aprendi o que fazer quando uma criança ou um bebezinho se afoga com comida ou objetos" (F7).

Machado e colaboradores (2017) evidenciaram em seu estudo que o conhecimento dos professores de Educação Infantil acerca de PS, vem de experiências adquiridas na vida pessoal, especialmente os vivenciados com os próprios filhos, conhecimentos esses aplicados no contexto escolar.

Diante do exposto, nota-se que promover capacitações sobre PS específicos para esta faixa etária aos profissionais que atuam na Educação Infantil é de suma importância, pois orientam como agir em nível pré-hospitalar, em casos de acidentes leves ou graves, aumentando as chances de sobrevida e de recuperação mais rápida das vítimas (BARROS, 2011; RITTER et al., 2013).

\section{$5^{a}$ Categoria: Importância e necessidade da presença do profissional enfermeiro}

A última categoria diz respeito à importância e à necessidade da presença do profissional enfermeiro na escola. Como evidenciado durante o estudo, 100\% dos entrevistados são a favor de, pelo menos, visitas periódicas deste profissional ao estabelecimento escolar, visto poder auxiliar os colaboradores quanto a assuntos relacionados à saúde, como evidenciado nos relatos:

"(...) eu acho muito importante, não só nos momentos de emergência, mas também para orientações, como assuntos relacionados à saúde, vacinas, acompanhamento do crescimento, higiene, etc." (F1).

"(...) com certeza é importante, pois por mais que a gente saiba fazer, na hora ficamos nervosas e acabamos esquecendo algumas coisinhas podendo prejudicar ao invés de ajudar" (F5).

Relatos que reforçam a importância da presença do enfermeiro na escola, ocupando um papel relevante na prevenção e identificação precoce de alteração ou agravo no processo de desenvolvimento infantil, na assistência global, contribuindo para a educação e a socialização das crianças (GIJSEN; KAISER, 2013; CABRAL, 2015).

Esses relatos corroboram com a pesquisa de Machado e colaboradores (2017) ao constatarem que o profissional enfermeiro deveria pertencer ao quadro de funcionários da escola. Os autores salientam que os enfermeiros escolares estão envolvidos na prevenção e na identificação precoce de patologias e no tratamento relacionado a maus tratos à criança, pela oportunidade de interagir com ela em uma base diária (RITTER et al., 2013; SIEBENEICHLER; HAHN, 2014).

Nesse sentido, o enfermeiro exerce um papel fundamental para a população, pois pratica atividades e programas voltados à educação em saúde, adequando um avanço da saúde do sujeito, da família e da localidade. A representação deste profissional como educador faz com que ele se sobressaia em ambientes pedagógicos da saúde, é componente de sua profissão, é arte e ciência (GIJSEN, KAISER, 2013). 
Bonetti e colaboradores (2010) e Tinoco, Reis e Freitas (2014) reforçam a importância do profissional da saúde compartilhar sua prática de cuidado com professores, ampliando o conhecimento desses e contribuindo para a promoção da saúde ao construir estratégias conjuntas de prevenção a acidentes (CABRAL, 2015).

\section{$2^{a}$ Fase da pesquisa: Simulação prática e feedback}

A segunda etapa deste estudo foi concretizada na realização de testes em forma de simulação de situações de emergência. Utilizou-se para a realização, imagens, bonecos e relatos dessas situações e em seguida foi observada a atitude dos participantes frente às intercorrências de emergência, elencadas previamente durante as entrevistas com a amostra.

O planejamento e o desenvolvimento dos testes apoiaram-se, teoricamente, em checklist criada apartir do Protocolo de Suporte Básico de Vida (BRASIL, 2016). Destacaram-se as seguintes temáticas: desmaio, engasgo, convulsão e epistaxe. Abordando conceitos, possíveis causas e modos de intervenção de PS.

Inicialmente, foi descrita a temática de epistaxe, e em seguida observaram-se as principais intervenções recomendadas, com descrição prática e dinâmica dos participantes durante as intervenções. Assim, seguiu-se a mesma metodologia na abordagem dos demais temas.

Contudo, ficou evidente durante a observação das atividades práticas, conhecimento insuficiente das participantes a respeito das técnicas intervencionistas. No manejo inicial e no acionamento da ajuda de urgência, quando necessário, além de não relacionarem a execução do atendimento com a adoção de posturas corporais adequadas. As participantes apresentaram descuido no contato com secreções e fluidos sanguinolentos, demonstrando que não possuem conhecimento acerca de contaminações.

Essas experiências vivenciadas pelas professoras possibilitaram aproximar a discussão de suas realidades. Já o compartilhamento serviu de base para a avaliação final realizada após a execução das atividades. As situações foram descritas buscando manejar o debate sobre as intervenções realizadas nas abordagens vividas, e como procederiam caso presenciassem novamente as ocorrências, após a participação na atividade prática e educativa.

Algumas dúvidas ainda presentes foram esclarecidas, essas se referiam ao acionamento de familiares; como realizar os registros; o uso do kit de PS; tumulto dos escolares e a busca por serviço especializado.

O professor, diante de uma situação de acidente, vê-se na incumbência de auxiliar a criança, muitas vezes fazendo uso de conhecimentos populares que podem ser prejudiciais (RITTER et al., 2013; SILVA et al., 2017).

Observa-se na tabela 3, quando vista da esquerda para a direita, respectivamente, o tipo de agravo, atitudes realizadas pelos participantes e sequências de atitudes indicadas e esperadas a se observar durante as simulações (BRASIL, 2016). A somatória das ações realizadas extrapola o número real da amostra, pois cada participante realizou mais de uma ação.

Durante a análise dos resultados da tabela 3, observou-se no primeiro agravo "epistaxe", que 64\% dos participantes erraram a conduta perante esse episódio, inclinando a cabeça da criança para trás, e por se tratar de uma ocorrência frequente, confirma a importância da educação em saúde para a conduta correta. Nesse caso, Silva e colaboradores (2017) afirmam que o procedimento correto 
é manter a pessoa sentada, inclinando a cabeça para frente, evitando assim que o sangue vá para a garganta e seja engolido, provocando náuseas.

Esses resultados vêm ao encontro dos achados em pesquisas semelhantes, em que $64 \%$ dos participantes erraram na conduta a ser tomada (TINOCO; REIS; FREITAS, 2014; SILVA et al., 2017).

Em relação às atitudes dos participantes frente à ocorrência de desmaio, verificou-se que 82\% não apresentaram conhecimento e realizaria ações inadequadas, como ao oferecer água à criança, porém, dentre eles 73\% encaminharia o escolar ao Pronto Socorro ou UBS de referência (MACHADO et al., 2017; SILVA et al., 2017; LINO et al.,2018).

As medidas gerais para tratamento, no que diz respeito a desmaios, são manter a vítima deitada, com a cabeça abaixo do nível do corpo para aumentar a circulação sanguínea no cérebro, afrouxar roupas apertadas, não ofertar nada para o paciente comer ou beber, o que pode causar broncoaspiração, e caso esteja em local mal ventilado, providenciar a remoção para outro local mais apropriado (COELHO; SILVA, 2011; OLIVEIRA et al., 2012).

Sobre a conduta a ser realizada durante uma crise convulsiva pôde-se observar que $45 \%$ da amostra tentou abrir ou introduzir algo na boca da criança, com a intenção de proteger a língua ou para que respirasse melhor e, dessa forma, acabaria rapidamente o período de sua crise convulsiva. Entretanto, como instruído pela literatura, esta ação pode prolongar o período de convulsão e causar alguma lesão. Já a tentativa de abrir a boca poderia ocasionar um novo acidente. (COELHO; SILVA, 2011; OLIVEIRA et al., 2012; SILVA et al., 2017).

Em relação à conduta seguida pelos participantes frente á situação de engasgo, verificou-se que $64 \%$ dos participantes acionaram o serviço de emergência e realizaram a manobra de Heimlich, fato esse que vai ao encontro dos achados literários, que relatam a aplicação da manobra pelos professores da Educação Infantil em casos de engasgo (VOLPATO; VITOR; SANTOS, 2014; GONÇALVES, 2011).

De acordo com Silva e colaboradores (2012), a manobra de Heimlich serve para a desobstrução de vias aéreas por corpo estranho.

As dificuldades do manejo, em casos de acidentes escolares, são confirmadas na literatura pela deficiência de conhecimentos, por parte dos docentes, acerca das condutas corretas a serem tomadas em diferentes situações, pois sentem-se parcialmente preparados para atender às situações simples, no entanto, apresentam dúvidas quanto à gravidade das lesões e não se sentem preparados para prestar essa assistência, evidenciando comportamento inseguro (OLIVEIRA et al., 2012; SIEBENEICHLER; HAHN, 2014; SILVA et al., 2017). 
Tabela 3: Demonstrativo das atividades desenvolvidas durante a simulação das situações de emergência.

\begin{tabular}{|c|c|c|}
\hline $\begin{array}{l}\text { TIPO } \\
\text { DE AGRAVO }\end{array}$ & ATITUDE OBSERVADA & SEQUÊNCIA DE ATITUDES INDICADAS \\
\hline Epistaxe & $\begin{array}{l}\text { [2] Lavar e deixar o sangue escorrer. } \\
\text { [4] Estimulara criança a assoar o nariz e } \\
\text { inclinar a cabeça para trás. } \\
\text { [2] Lavar até parar o sangramento. } \\
\text { [4] Colocar gaze, algodão ou qualquer } \\
\text { outro objeto similar dentro da região nasal. } \\
\text { [1] Molhar a nuca. } \\
\text { [2] Deitar a criança e deixar o sangue sair. } \\
\text { [8] Elevar a cabeça. } \\
\text { [1] Elevar a criança. } \\
\text { [3] Manter a cabeça reta e, se necessário, } \\
\text { incliná-la para frente e para baixo. }\end{array}$ & $\begin{array}{l}\text { Colocar a criança sentada, em local fresco e arejado. } \\
\text { Manter a cabeça reta e, se necessário, incliná-la para frente } \\
\text { e para baixo, a fim de evitar a deglutição do sangue. } \\
\text { Orientar a criança para apertar a narina que está sangrando. } \\
\text { Se comprimir as duas narinas, orientar para que respire pela } \\
\text { boca. } \\
\text { Caso o sangramento não cesse, colocar um saco de gelo } \\
\text { envolvido em pano limpo sobre a testa do escolar, por cerca } \\
\text { de } 20 \text { minutos, mantendo a compressão das narinas contra o } \\
\text { septo. } \\
\text { Encaminhar para o Pronto Socorro de referência, } \\
\text { especialmente os casos de trauma. }\end{array}$ \\
\hline Desmaio & $\begin{array}{l}\text { [1] Pegar no colo e sair correndo em busca } \\
\text { de ajuda. } \\
\text { [2] Jogar a criança para cima. } \\
\text { [7] Dar água para beber. } \\
\text { [5] Não souberam como agir. } \\
\text { [3] Passar álcool no nariz e na nuca. } \\
\text { [1] Tirar a língua para fora. } \\
\text { [1] Manter a criança em pé. } \\
\text { [2] Dar tapinhas no rosto. } \\
\text { [8] Encaminhar o escolar para o Pronto } \\
\text { Socorro ou UBS de referência. }\end{array}$ & $\begin{array}{l}\text { Manter a tranquilidade e afastar os curiosos. } \\
\text { Deitá-lo de costas com as pernas mais elevadas do que o } \\
\text { corpo. } \\
\text { Afrouxar as roupas. } \\
\text { Após o escolar recuperar a consciência, deixá-lo deitado por } \\
5 \text { minutos e depois por } 05 \text { minutos, sentado, para evitar novo } \\
\text { desmaio. } \\
\text { Encaminhar o escolar para o Pronto Socorro ou UBS de } \\
\text { referência. }\end{array}$ \\
\hline Engasgo & $\begin{array}{l}\text { [1] Virar a criança de cabeça para baixo } \\
\text { ou levantar os braços da criança. } \\
\text { [2] Bater nas costas. } \\
\text { [1] Pegar no colo e jogar para cima. } \\
\text { [1] Observar atentamente. } \\
\text { [7] Executar a manobra de Heimlich. } \\
\text { [2] Bater nas costas. }\end{array}$ & $\begin{array}{l}\text { Acalmar o paciente. } \\
\text { Incentivar tosse vigorosa. } \\
\text { Observar atenta e constantemente. } \\
\text { Se evoluir para obstrução grave: executar a manobra de } \\
\text { Heimlich. }\end{array}$ \\
\hline $\begin{array}{l}\text { Crise } \\
\text { Convulsiva }\end{array}$ & $\begin{array}{l}\text { [2] Abrir a boca para colocar pano, a fim } \\
\text { de evitar morder a língua. } \\
\text { [1] Transportar a vítima durante a crise. } \\
\text { [5] Segurar a criança. } \\
\text { [1] Jogar água ou bater no rosto da vítima } \\
\text { na tentativa de acabar com a crise. } \\
\text { [1] Procurar algo na boca usando os } \\
\text { dedos. } \\
\text { [2] Segurar a língua. } \\
\text { [2] Segurar a criança em pé e chamá-la. } \\
\text { [1] Pede ajuda a outra pessoa. } \\
\text { [5] Proteger a cabeça contra pancadas } \\
\text { no chão e procurar manter a cabeça } \\
\text { lateralizada, para evitar que a vítima } \\
\text { engasgue com a saliva. } \\
\text { [6] Acionar o SAMU. }\end{array}$ & $\begin{array}{l}\text { Manter a tranquilidade e procurar afastar os curiosos. } \\
\text { Se possível, proteger a vítima da queda. } \\
\text { Afastar objetos que possam causar ferimentos (móveis, } \\
\text { pedras, etc). } \\
\text { Afrouxar as roupas e retirar os óculos. } \\
\text { Proteger a cabeça contra pancadas no chão e procurar } \\
\text { manter a cabeça lateralizada, para evitar que a vítima } \\
\text { engasgue com a saliva (não realizar este procedimento se } \\
\text { houver suspeita de trauma na coluna cervical). } \\
\text { Acionar o SAMU. }\end{array}$ \\
\hline
\end{tabular}

Fonte: Autora (2018).

\section{CONSIDERAÇÕES FINAIS}

Após a análise dos resultados pôde-se observar o esforço e a dedicação dos pesquisados, não obstante mostraram dificuldade na execução das atividades, o que pode provocar danos irreversíveis, com consequências à vida dos alunos, assim como para os próprios professores.

A ausência do enfermeiro dentro das instituições, prática comum na maioria das escolas, e comprova pelos pesquisados, evidencia a necessidade e a importância deste profissional, não só na intervenção imediata e na prevenção de acidentes, mas em assuntos relacionados à saúde, 
garantindo assim a qualidade de saúde dos alunos e a sensação de segurança, tanto aos professores quanto aos pais.

Dessa maneira, a presença de enfermeiros em escolas de Educação Infantil, proporcionaria aos educadores, demais colaboradores da educação e pais de escolares, mais conforto e segurança, principalmente aos pais de crianças com doenças crônicas e portadores de deficiências físicas.

Outra alternativa seria a inclusão de atividades no período acadêmico na forma de horas complementares e também dentro de disciplinas como Educação em Saúde, Enfermagem em Saúde Coletiva e Enfermagem na Saúde da Criança, aproximando consideravelmente o cenário prático à formação acadêmica.

Estimular, de forma contínua, a participação dos professores em eventos que ajudem no aprimoramento profissional da equipe, específicos à faixa etária em questão, o que contribuiria sem dúvida para a diminuição dos riscos, dando maior ênfase à conscientização do que são acidentes, suas consequências e medidas de prevenção.

A implantação de registros dos agravos ocorridos, servindo de apoio para maior conscientização do problema e redirecionamento de ações pontuais, as quais possibilitariam conhecimento a respeito de sua prevenção, como a prática de um checklist com procedimento operacional padrão (POP), o qual uniformizaria os protocolos, de acordo com o recomendado, facilitando o treinamento e proporcionando segurança aos funcionários.

Portanto, o enfermeiro tem significativa importância do cuidado saúde-educação, no ambiente escolar, ao investigar, avaliar e/ou intervir em diferentes elementos como adaptação da criança e da família à instituição, alimentação, sono e repouso, prevenção de acidentes e doenças, promoção da saúde, assim como nos diferentes aspectos do acompanhamento do crescimento e desenvolvimento físico e emocional, contextualizando-os em uma proposta de cuidado à criança nas escolas de Educação Infantil.

Reconhece-se a limitação da pesquisa devido à pequena amostra e fontes de pesquisas escassas, revelando a pouca produção de artigos que abordem o assunto por enfermeiros, o que motiva novas pesquisas, investigando as variáveis que não foram foco desta pesquisa, como a não presença do enfermeiro em todas as instituições de Educação Infantil.

Ressalte-se a relevância desta pesquisa, na medida em que contribuiu para a atenção aos profissionais e aos escolares, pois este estudo trouxe respostas quanto à situação atual e recomendações importantes para a solução das problemáticas reveladas ao longo desta pesquisa-ação. Assim como é necessário considerar a sua contribuição social, ao modificar o cotidiano dos funcionários, direcionando novas práticas a serem introduzidas e melhoradas, permitindo-lhes um conhecimento técnico atualizado, abarcando também novos desafios para o enfermeiro educador.

\section{REFERÊNCIAS}

BARROS; L. S. Prevenção de acidentes em um centro de Educação Infantil de Araguaína - TO. 2011. 25 p. Relatório Analítico (Especialização em Coordenação Pedagógica) - Curso de PósGraduação Lato Sensu em Coordenação Pedagógica, Araguaína - TO, 201 1. Disponível em: <http://coordenacaoescolagestores.mec.gov.br/uft/file.php/1/moddata/data/1003/1221/2306 / TCC_FINAL_-_LEICIJANE.pdf >. Acesso em: $30 \mathrm{fev} .2018$. 
BONETTI, K. G. et al. Prevenção de Injúrias não Intencionais na infância: Uma Revisão Integrativa. 2010. 53 p. Trabalho de Conclusão de Curso (graduação) - Curso de Enfermagem da Universidade Federal do Pampa, Uruguaiana, 2010.

BRASIL. Lei n. 8.069, de 13/07/1990. Dispões sobre o Estatuto da Criança e do Adolescente e dá outras providências. Brasília, DF, 1990. Disponível em: <http://www.planalto.gov.br/>. Acesso em: 10 fev 2018.

BRASIL. Programa Saúde na Escola (PSE). Decreto n. 6.286, de 5 de dezembro de 2007.

BRASIL. Congresso Nacional. Lei n 9.394, de 20 de dezembro de 1996. Brasília; 1996

BRASIL. Ministério da Saúde. Secretaria de Atenção à Saúde. Protocolos de Intervenção para o SAMU 192 - Serviço de Atendimento Móvel de Urgência. Brasília: Ministério da Saúde, 2016.

CABRAL, E.V.. Primeiros socorros na educação básica: contribuição do enfermeiro para a capacitação docente./Elaine Viana Cabral. - Volta Redonda: UniFOA, 2015.

CALANDRIM, L.F. et al.. Primeiros socorros na escola: treinamento de professores e funcionários. Rev Rene. 2017 maio-jun; 18(3):292-9.

CRIANÇA SEGURA SAFE KIDS BRASIL. 15 Anos de atuação da criança segura no Brasil. Agosto de 2016. Disponível em: <http://criancasegura.org.br/wp-content/uploads/2016/10/livreto-15-anosv2D-2016-08-29-simples.pdf>. Acesso em: 17 fev. 2018.

COELHO, Luíz Cláudio Araújo; SILVA, Lidiane Rodrigues Campelo. Formação Docente, Educação e Prevenção de Acidentes. X Congresso Nacional de Educação (EDUCERE), 2011.

COSTA, A. C. P. J. et al. Prevenção de acidentes em crianças e adolescentes na estratégia saúde da família. Revenferm UERJ, Rio de Janeiro, 2015 set/out; 23(5):668-73.

GIJSEN, L. I. P. S.; KAISER, D. E. Enfermagem e educação em saúde em escolas no Brasil: revisão integrativa da literatura. CiencCuidSaude Out/Dez, 2013.

GONÇALVES M. E. P; CARDOSO, S. R; ASCENDINO, A.J ,Corpo Estranho em Via Aérea , Pulmão RJ $2011 ; 20(2): 54-58$.

LINO,C. M.et al.Acidentes com crianças na educação infantil: percepção e capacitação de professores/cuidadores Rev. em Saúde., Piracicaba, v. 18, n. 48, p. 87-97, jan.-abr. 2018.

MACHADO, E.C.M. et al. Acidentes na infância: percepção e atitudes dos professores na educação infantil. Revista Saúde e Desenvolvimento. vol.11 n.7; abr/jun. 2017.

MAIA, M.F.M.; ANJOS, M. R. R.; MIRANDA NETO, J. T.; GOMES, M. C. S.; DEUS- DARÁ F. F. Primeiros socorros nas aulas de educação física nas escolas municipais de uma cidade no norte do estado de Minas Gerais. Coleção Pesquisa em Educação Física, v. 11, n. 1, ISSN: 1981-4313. 2012.

MALTA, D.C. et al.. Acidentes e violência na infância: evidências do inquérito sobre atendimentos de emergência por causas externas - Brasil, 2009. Ciência e Saúde Coletiva, Rio de Janeiro, v. 17, n.9, p. 2247-2258. 2012.

MINAYO, M. C. S. O desafio do conhecimento: Pesquisa qualitativa em saúde. $13^{a}$ Ed. São Paulo, SP: Editora Hucitec, 2013.

MINAYO, M. C. S. Introdução à metodologia de pesquisa social. In: O desafio do

conhecimento: pesquisa qualitativa em saúde. 8. ed. São Paulo: Hucitec, 2004. cap. 1, p. 19-88. 
OLIVEIRA, A.S, et al.. Atuação dos Professores às crianças em casos de acidentes na escola. Rev. Interdisciplinar. UNINOVAFAPI 2012; 5(3): 26-30.

RITTER, N. S. et al. A importância de se trabalhar o conhecimento de socorros em âmbito escolar. In: SEMINÁRIO INTERNACIONAL DE EDUCAÇÃO NO MERCOSUL. 2013, Cruz Alta. Anais eletrônicos.... Cruz Alta: PARFOR-UNICRUZ, Rio Grande do SUl. 2013.

RNPI - REDE NACIONAL PRIMEIRA INFÂNCIA. Acidentes na Primeira Infância. Disponível em: <http:// www.fmcsv.org.br/pt-br/acervo-digital/paginas/evitando-acidentes-na-primeira-infancia.aspx>. Acesso em 18 de fev. de 2018.

SENA S.P.; RICA, J.;VIANA, M.R. A. percepção dos acidentes escolares por educadores do ensino fundamental, Belo Horizonte. Rev. méd. Minas Gerais, Belo Horizonte, v. 18, n. 4, p. 47-54, nov. 2008.

SIEBENEICHLER, A. E. M.; HAHN, G. V. Professores da pré-escola e o agir em situações de emergência. Revista Destaques Acadêmicos, v. 6, n. 3, p. 139- 147, 2014.

SILVA, L. G. S. et al. Primeiros socorros e prevenção de acidentes no ambiente escolar: intervenção em unidade de ensino. Enferm. Foco 2017; 8 (3): 25-29.

SIQUEIRA, G.S.; SOARES, L.A.; SANTOS, R.A. Atuação do professor de Educação Física diante de situações de primeiros socorros. EFDEPORTES.COM, Revista digital. Buenos Aires, Arg. v.15,n.154, mar. 2011.

THIOLLENT, M. Metodologia da Pesquisa-ação. 10. ed. São Paulo: Cortez: Autores Associados, 2000. (Coleção temas básicos de pesquisa-ação).

THIOLLENT, Michel. Metodologia da pesquisa-ação. 18. ed. São Paulo: Cortez, 2011.

TINOCO, V. do A.; REIS, M. M. T., FREITAS, L.N. O Enfermeiro Promovendo Saúde como Educador Escolar: atuando em primeiros socorros. Revista Transformar. Centro Universitário São José de Itaperuna, RJ. 2014.

VASCONCELOS, F.V.P.; POCAHY, F.A.. "Não é a mamãe?": a presença de homens educadores como elemento na problematização da agonística social da feminização da educação infantil. Textura, n. 28, p. 129- 46, mai/ago. 2013. Disponível em:<www.periodicos.ulbra.br/index.php/txra/ article/download/929/706>. Acesso em 07 de fev de 2018.

VOLPATO, A. C. B.; VITOR, C. S.; SANTOS, M. A. M. (Org.). Enfermagem em emergência . 2. ed. São Paulo: Martinari, 2014. p. 396. 